
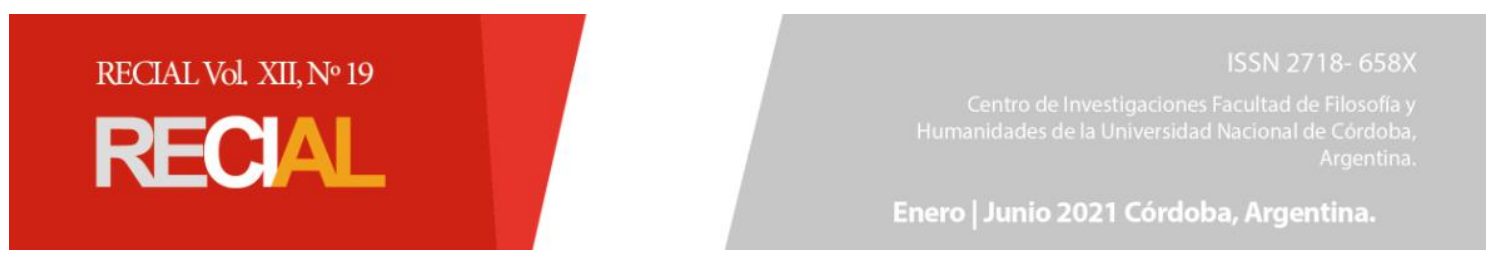

\title{
Por el camino de las palabras: tiempo, memoria y escrituras del yo en Marcel Proust y Natalia Ginzburg
}

Hebe Castaño*

\section{Resumen}

Existe una relación innegable entre Marcel Proust y Natalia Ginzburg. Sus respectivas obras, À la recherche du temps perdu y Lessico famigliare, entablan un diálogo intertextual profundo y productivo. Esta relación ha sido ya mencionada en numerosos estudios críticos en lengua italiana, pero en español son pocos los que exploran ese diálogo entre ambos autores, sus poéticas y sus textos. El propósito de este trabajo es, entonces, iniciar un estudio comparativo sobre determinados aspectos de ambas obras que permita delimitar y precisar algunas de las características que las enlazan. Nuestro trabajo parte de una breve pero necesaria contextualización sobre la traducción y recepción de Proust en Italia y luego se centra en el análisis de determinados aspectos presentes en ambas obras, tales como la memoria y el léxico, las palabras de la tribu y las de los otros, los lugares de la memoria y las autofiguraciones de los escritores cuando niños.

Dado que nuestro tema de estudio involucra la memoria y las escrituras del yo, los aportes teóricos de Paul Ricoeur en relación con la memoria, y los de Paul de Man y Mijaíl Bajtín en lo que concierne al estatuto de la escritura autobiográfica, nos guían en el análisis de ambos textos.

Palabras clave: memoria, léxico, familia, espacios, autobiografía

\section{Along the way of words: time, memory and writings of the self in Marcel Proust and Natalia Ginzburg}

\begin{abstract}
There is an undeniable relationship between Marcel Proust and Natalia Ginzburg. Their respective works, $\grave{A}$ la recherche du temps perdu and Lessico famigliare, engage in a deep and productive intertextual dialogue. This relationship has already been mentioned in numerous critical studies in Italian language, but in Spanish there are few that explore this dialogue between the two authors, their poetics and their texts. The purpose of this work is, then, to initiate a comparative study on certain aspects of both works, which allows to delimit and specify some of the characteristics that link them. Our work starts with a brief but necessary contextualization on the translation and reception of Proust in Italy and then focuses on the analysis of certain aspects which are present in both works, such as memory and lexicon, the words of the tribe and others, the places of memory and the autofigurations of the writers as children.
\end{abstract}

\footnotetext{
" Doctora en Letras, profesora a cargo de Literatura Europea II de la Universidad Nacional del Comahue, Neuquén, Argentina. hebe_cast@yahoo.com.ar Recibido: 13/02/2020. Aceptado: 20/05/2021.
} 
Considering that our subject of study involves memory and the writings of the self, the theoretical contributions of Paul Ricoeur in relation to memory, and those of Paul de Man and Mikhail Bakhtin regarding the status of autobiographical writing, have guided us in the analysis of both texts.

Keywords: memory, lexicon, family, spaces, autobiography

Después de mucho tiempo, me he dado cuenta de que he buscado y encontrando en Proust algo que me servía a mí, para mis escritos. Autores similares, con los cuales se entabla una relación de estrecho e íntimo diálogo, se encuentran pocos, en la vida...

Natalia Ginzburg

I.

Jorge Luis Borges advirtió, con su acostumbrada lucidez teórica, que cada escritor crea sus propios precursores. Sin lugar a dudas, es el caso de la relación existente entre Natalia Ginzburg y Marcel Proust, cuyas obras respectivas, Lessico famigliare y À la recherche du temps perdu, entablan un diálogo intertextual evidente y productivo. Esta relación ha sido mencionada como marca insoslayable en numerosos estudios críticos en lengua italiana, pero en español son pocos los que exploran ese innegable diálogo entre ambos autores, sus poéticas y sus textos. El propósito de este trabajo es, entonces, iniciar un estudio comparativo sobre determinados aspectos de ambas obras que permita delimitar y precisar algunas de las características que las enlazan. Para ello nos centraremos en los dos primeros volúmenes de la obra proustiana, Du côté de chez Swann, y en la novela más importante de la producción ginzburiana, Lessico famigliare, que en 1963 llevó definitivamente a su autora a la fama y le otorgó un lugar relevante en el concierto de la literatura italiana contemporánea.

Una razón fundamental sobre cómo se ha recortado el corpus de textos tiene que ver con el hecho de que Natalia Ginzburg tradujo Du côté de chez Swann del francés al italiano, un trabajo que comenzó para la editorial de Giulio Einaudi en $1937^{1}$. Su laboriosa traducción y el amor que siempre tuvo hacia el escritor francés no solo dejó la impronta en el título de una de sus primeras novelas, La strada che va in città, publicada en 1942, sino que, además, dio presencia en Lessico famigliare a Proust como escritor y a su obra, no solo a través de numerosas menciones de innegable importancia y valor que permiten comprender la gravitación del autor francés en la cultura italiana de los años 30 y en la propia historia familiar de los Levi a ella vinculada, sino también tomando y transformando aspectos constitutivos de ese universo narrativo, como por ejemplo, la relación de las palabras y la memoria.

Nuestro trabajo se estructura del siguiente modo: en primer lugar, haremos una breve pero necesaria contextualización sobre la traducción y recepción de Proust en Italia; a continuación, desarrollaremos propiamente nuestro análisis, para lo cual hemos seleccionado dos aspectos fundamentales que nos permitirán plantear cuestiones de fondo entre ambos autores: 1) memoria y léxico; 2) las palabras de la tribu y las de los otros; 3) los lugares de la memoria; 4) autofiguraciones de escritores niños: infancia y soledad. Dado que nuestro tema de estudio involucra la memoria y las escrituras del yo, apelaremos a diversos aportes teóricos, como los de Paul Ricoeur en La memoria, la historia y el olvido, texto que nos provee algunas diferenciaciones sobre términos como memoria, recuerdo, olvido y rememoración, entre otros no menos importantes. También, en relación con la autobiografía, subyacen en nuestro estudio los supuestos teóricos de Paul de Man y Mijaíl Bajtín, en cuanto entienden respectivamente la escritura autobiográfica como una construcción del lenguaje y como un discurso bifronte que supone, por un lado, un acto de conciencia (un cronotopo 
interno sobre el tiempo-espacio de una vida) y, por otro, un acto de comunicación (un cronotopo externo que implica la representación pública de esa vida).

\section{De traducciones e influencias: Proust en Italia}

Giulio Ferroni (2017) rastrea la impronta de Proust en varias escritoras italianas de la segunda posguerra y verifica cómo la obra del escritor francés se proyecta y transforma en ellas, especialmente en lo que concierne al carácter de la memoria y la percepción del tiempo, desde la original traducción de Natalia Ginzburg hasta La penombra che abbiamo attraversato, de Lalla Romano.

La influencia de Proust alcanza a escritoras como Anna Banti (1895-1985), Anna Maria Ortese (1914-1998), Elsa Morante (1912-1985), Francesca Sanvitale (1928-2011) y Fabrizia Ramondino (1936-2008), un fenómeno que lleva a Ferroni a interrogarse sobre el porqué de esta huella en la escritura de mujeres. Lejos de conformarse con respuestas demasiado convencionales, observa que muchas de estas escritoras del siglo XX exhiben una sensibilidad que centra su atención en lo particular inadvertido, en la indagación que lleva más allá de la superficie de las cosas, en la búsqueda de una verdad "che va al di là della scorza externa delle cose e che si cerca sopratutto entro le occorrenze dell'esistere, nell'evocazione dell'infanzia e del mondo familiare, nella percezione animata dello spazio, nei sussueti e nelle alterazioni del tempo" (Ferroni, 2016, p. 20). Traducción:

Que va más allá del caparazón externo de las cosas y que se busca sobre todo dentro de los acontecimientos de la existencia, en la evocación de la infancia y el mundo familiar, en la percepción animada del espacio, en los cambios y alteraciones del tiempo. (Ferroni, 2016, p. 20).

Aspectos todos que confirman la presencia de Proust en la escritura de la novela más famosa de la Ginzburg, especialmente en lo que concierne a la construcción de un lenguaje familiar que reenvía a la primera parte de Du côte de chez Swann, pero que de ningún modo imita. En todo caso, y esta es una cuestión que destaca Ferroni (2016), Proust operó en las escritoras italianas una influencia tan determinante como impulsora de nuevas tendencias a partir de él.

Es necesario destacar que, en la Italia de los años 30, leer y estudiar a Proust significaba aceptar un lugar incómodo en relación con el fascismo dominante en la vida política y cultural del país, totalitarismo que promovía una literatura netamente local, nacional, enemiga de todo lo proveniente del extranjero. Fue luego de la promulgación de las leyes raciales del mussolinismo que el escritor francés se convirtió en uno de los objetivos del antisemitismo de Estado (Piazza, 2016). Por otra parte, si los intelectuales antifascistas de izquierda desconfiaban de una escritura con rasgos tan elitistas como la del autor de la Recherche..., las críticas negativas que el reconocido Benedetto Croce había enunciado sobre la obra despertarían paralelamente entre ellos un cierto entusiasmo (Abes, 2020).

Teniendo en cuenta la complejidad del contexto italiano y un ambiente no demasiado propicio para los escritos proustianos, hay que considerar la relevancia de la primera traducción de la Ginzburg, un verdadero desafío que - según ella misma relató años después - aceptó sin haber leído aún el libro del que tanto había escuchado hablar en su familia. Tal como lo señala en su artículo Mariolina Bertini (2014), desde entonces y para toda una generación de posguerra italiana, los nombres de Natalia Ginzburg y Marcel Proust 
permanecen indiscutiblemente unidos en la literatura de ese país, y esto por muchos motivos, como ya veremos más adelante en nuestro análisis específico.

Unos diez años después de la muerte de Proust, acaecida en 1922, algunos críticos italianos comenzaron a ocuparse de su obra. En 1933, aparecieron las primeras monografías escritas en italiano sobre el autor y en 1937 Natalia Ginzburg aceptó hacer la traducción del primer volumen de la Recherche para la editorial de Giulio Einaudi, la cual finalmente fue publicada en 1946. Desde este último año hasta 1983, la mayoría de los lectores italianos de Proust lo había leído a través de la mediación de la voz de la autora de Lessico famigliare y, si bien le sucedieron otras voces en la traducción de los numerosos volúmenes de la obra proustiana $^{2}$, el íncipit tiene la marca de la autora (Bertini, 2014). El título elegido en italiano para la traducción de la Ginzburg fue La strada di Swann, el cual fue sugerido por Leone Ginzburg, el marido de Natalia, quien, junto a Giulio Einaudi, dueño de la importante editorial italiana, le había propuesto que hiciera la traducción de la Recherche...

La obra de Proust, como ya hemos dicho, está íntimamente vinculada a la Ginzburg no solo porque hacer la traducción del primer volumen de Du côté de chez Swann le llevó a la escritora más de ocho años, en los que tuvieron lugar muchos y graves sucesos en su vida, sino también porque las aproximaciones a Proust y a su monumental obra se relacionan con vivencias familiares. Así, por ejemplo, Proust había sido constantemente traído a colación en lo cotidiano por la madre de Natalia y los hermanos mayores, que habían leído la Recherche en francés, una lectura que es marca de cultura de una burguesía más o menos acomodada, antifascista y abierta a las influencias de escritores extranjeros. Como advertía el propio Giulio Einaudi, la obra de Proust traducida al italiano se difundiría seguramente entre "personas inteligentes", y los antifascistas Levi, por el solo hecho de ser opositores a ese totalitarismo, podrían considerarse dentro de esa categoría ${ }^{3}$.

En 1963, Natalia Ginzburg dejó testimonio de la experiencia de traducción de Du côté de chez Swann en "Cómo he traducido Proust" (2017a). Allí confesaba, con ese tono que siempre convoca al lector a la complicidad con el narrador, que había aprendido lo que significaba traducir con Proust. Describía la experiencia como un trabajo que debía combinar la minuciosidad de la hormiga y el ímpetu del caballo. Con su acostumbrada estrategia de fingir un yo obtuso, ignorante o incapaz, sostenía en el mismo texto no poseer ese arte y que esa tarea solo podía llevarla a cabo si se enamoraba de lo que estaba traduciendo.

Todo lo que sabía de Proust, era lo poco que había oído de él en mi casa, todavía en la época de mi infancia: habían sido pronunciados en mi presencia los nombres de Odette y de Swann; y como yo había preguntado, creo, quién diablos era este Proust, me habían respondido que era un niño, el cual quería darse un paseo por una calle, con el objetivo de ver una niña que le gustaba, pero sus padres lo llevaban, en cambio, por otra: un niño que amaba los espinos blancos (yo tenía también, de pequeña, en mi jardín, matorrales de espinos blancos, pero no me importaba nada). (Ginzburg, 2017a, p. 142).

Proust se enlaza con las vivencias personales y profesionales de Natalia Ginzburg. No se trataba solamente de leer al autor francés y experimentar lo que su obra despertaba en ella, sino que iba mucho más allá: había una relación amorosa con el autor de la Recherche porque le hacía evocar conversaciones de familiares en el pasado, le traía recuerdos amados de su marido y mentor, en definitiva, la hacía pensar en ella misma.

Traducir Proust significó una experiencia vital y escrituraria única porque buscó en el autor francés algo que le servía a ella misma y a sus escritos (Ginzburg, 2017a, pp. 142-143). 
Ciertamente, no fue una lección de estilo. Nada más alejado del estilo de la Ginzburg "el laberinto de aquellas frases tan largas" (Ginzburg, 2017a, p. 142), por ejemplo. Tampoco esa ralentización proustiana que se convierte casi en una rémora, cuando el narrador se detiene en las mínimas cosas, en sus impresiones y sensaciones. Por el contrario, la autora del Lessico exhibe un estilo claro, tan conciso que cae en la reticencia, más cercano al de Hemingway, a quien ella también admiraba.

Lo más probable es que la fascinación por Proust haya venido de la mano del deseo de recobrar el tiempo, de la necesidad de recuperar lo vivido entre hermanos y padres a través de las palabras dichas, aquellas que vale la pena defender contra el olvido porque dan identidad, llevan a reconocerse y a reconocer a los integrantes de la tribu: son "la testimonianza d'un nucleo vitale che ha cessato di esistere, ma che sopravvive nei suoi testi, salvati dalla furia delle acque, dalla corrosione del tempo" (Ginzburg, 1999, p. 22) ${ }^{4}$ o, traducido, "el testimonio de un núcleo vital que ya no existe, pero que sobrevive en sus textos, salvados de la furia de las aguas, de la corrosión del tiempo" (2017b, pp. 37-38) ${ }^{5}$.

Hay, entonces, una línea vital y creativa que une la traducción de Du côté de chez Swann con Lessico famigliare. Es posible observar algunas correspondencias entre las decisiones que tomó Natalia como traductora y su particular e identificable estilo despojado y a la vez cercano y confidencial para el lector. Justamente, Giacomo Debenedetti, uno de los cultores italianos de Proust de la primera hora (aunque no precisamente el primero, como creía Natalia), advirtió en la traducción de la joven y osada traductora una serie de decisiones que transformaban injustificadamente el texto.

Bertini (2014), a partir de las observaciones de Debenedetti, se detiene en la comparación de las traducciones de Raboni y de Ginzburg, y ejemplifica los cambios operados por esta última. Concluye, sin embargo, más allá de las críticas que formulara Debenedetti, con que esas decisiones no fueron un forzamiento subjetivo y abusivo del texto proustiano, sino la prolongación de una dinámica que ya estaba presente, activa y desplegada en la escritora y que daría lugar, años después, en Lessico famigliare, a esas "voces que se entrecruzan" en su mundo poético familiar. En definitiva, lo que habría hecho Natalia Ginzburg y que muy lúcida y críticamente advirtió Debenedetti (sin tener idea de la futura existencia de Lessico) fue llevar a cabo en su traducción una especie de doblaje del idiolecto de los Levi al de los Proust, considerada una intrusión inadmisible para el especialista italiano ${ }^{6}$.

II.

\section{Memoria y léxico}

¿De qué hay recuerdo?, ¿de quién es la memoria? Para Paul Ricoeur (2004), quien subraya la importancia de estas dos preguntas ineludibles ${ }^{7}$, la memoria tiene esencialmente un carácter objetal: uno se acuerda de algo y en ese acto de recordar son fundamentales los acontecimientos. Sin embargo, más que sobre hechos vividos o sucesos de una vida, el origen de la rememoración se produce, tanto en Du côté de chez Swann, de Marcel Proust, como en Lessico..., de Natalia Ginzburg, a partir de una búsqueda en torno a las palabras dichas.

En las obras de nuestro corpus, ambos escritores tuvieron como objeto de la memoria y la escritura, ya sea de un modo parcial el primero y total la segunda, el habla de los otros, familiares y amigos más cercanos. Llevaron adelante una operación en la que el léxico familiar y el entorno de amistades se volvió un acontecimiento ${ }^{8}$ que era necesario rescatar contra el olvido. Las palabras que se recuperan no siempre se corresponden con experiencias vividas por las voces enunciadoras, sino que muchas de ellas provienen de un tiempo y de unos personajes anteriores a quienes cuentan la historia. Frases que se constituyen, para todos aquellos que no forman parte del círculo familiar o de amistades, en una especie de "lenguaje 
cifrado" propio, el cual, por lo general, es necesario que el narrador explique e indague casi con una "actitud detectivesca" (Benjamin, 1929). Esas palabras dichas, que a menudo fueron repetidas en determinadas ocasiones, en un tiempo y un lugar por otros, adquieren, en términos de Ricoeur, el carácter de un "acontecimiento único" (2004, p. 42) que es importante recordar en el relato del pasado, al igual que sucede con el recuerdo de ciertos rostros, ciertas vivencias o determinados encuentros.

Recordemos que, para Proust (el primero en hacer posibles las memorias en el siglo XIX, según Benjamin), no se puede ir al encuentro del pasado a través de la memoria voluntaria, sino que el pasado y el presente se conectan a través de sensaciones que se interponen. Este tipo de recuerdo está ligado al cuerpo y al azar de las circunstancias y, por esto mismo, escapa a la voluntad consciente. Para poder redescubrir el pasado, es necesario que se produzca un encuentro espontáneo con algún objeto material en el que están enterrados los recuerdos. El objeto (la madeleine mojada en el té es el ejemplo más famoso) funciona, entonces, como un talismán capaz de evocar vivencias que el tiempo nos ha quitado. Natalia Ginzburg, por su parte, acuerda con Proust: el recuerdo no es voluntario, pero mucho menos casual, y, si hay un objeto material que pone en movimiento la memoria, ese es el lenguaje, el vocabulario de los propios antepasados. (Pettinotto, 2013).

La importancia de la palabra hablada, el relato de lo que otros dijeron en determinadas circunstancias, con sus entonaciones e intenciones, ocupa un lugar fundamental para la escritora italiana, y, sin lugar a dudas, resulta muy relevante para Proust. Este aspecto de la memoria centrado en lo discursivo hace que sus novelas expresen su modernidad a través de un marcado dialogismo, en los términos en que Bajtín lo ha señalado teóricamente.

Estamos de acuerdo con Vintila Horia en que es justamente la especial relación con el lenguaje lo que sitúa a Proust en una línea de destacada originalidad con respecto a otros escritores europeos de su época, tales como Rilke, Broch y Musil:

Proust anuncia el experimento extremista de Joyce, aprisionando el Verbo, haciendo de él su único aliado contra el olvido. A través del lenguaje logra salvarse y conseguir, al final de una larga y dura batalla llevada desde su cama de enfermo, la victoria final sobre el tiempo perdido, al que transfigura en un tiempo resucitado. Lo que aparentemente estaba muerto en el fondo de la memoria, sube otra vez a la superficie y se apodera de un organismo viviente, el lenguaje literario, bajo la forma de una obra maestra de la literatura. (1989, p. 210).

Horia advierte, al igual que lo hace Walter Benjamin (1929), que es el lenguaje de los salones lo que aprisiona en su escritura Marcel Proust, un lenguaje secreto que estaba declinando para cuando comienza a escribir la Recherche... y que el autor francés buscó eternizar no solamente empleando en su obra el vocabulario usado en esos ambientes, sino también imprimiendo aquel estilo en sus personajes, que, en definitiva, no son más que "fragmentos de la vida muerta de su autor" (Horia, 1989, p. 210), vidas de seres casi vegetales de una sociedad saturada que se alimenta del chisme (Benjamin, 1929) y de intercambios intrascendentes.

En Natalia Ginzburg, las palabras de la tribu funcionan como la madeleine proustiana: son el instrumento necesario de la memoria, el elemento esencial que afirma no solo los lazos familiares, sino los más estrechos con el pasado (Pettinotto, 2013), el personal y el colectivo: 
Noi siamo cinque fratelli. Abitiamo in città diverse, alcuni di noi stanno all'estero: e non ci scriviamo spesso. Quando c'incontriamo, possiamo essere, l'uno con l'altro, indifferenti o distratti. Ma basta, fra noi, una parola. Basta una parola, una frase: una di quelle frasi antiche, sentite e ripetute infinite volte, nel tempo della nostra infanzia. Ci basta dire: "Non siamo venuti a Bergamo per fare campagna" o "De cosa spusa l'acido solfidrico", per ritrovare a un tratto i nostri antichi rapporti, e la nostra infanzia e giovinezza, legata indissolubilmente a quelle frasi, a quelle parole. Una di quelle frasi o parole, ci farebbe riconoscere l'uno con l'altro, noi fratelli, nel buio d'una grotta, fra milioni di persone. Quelle frasi sono il nostro latino, il vocabolario dei nostri giorni andati, sono come i geroglifici degli egiziani o degli assirobabilonesi, la testimonianza d'un nucleo vitale che ha cessato di esistere, ma che sopravvive nei suoi testi, salvati dalla furia delle acque, dalla corrosione del tempo. Quelle frasi sono il fondamento della nostra unità familiare, che sussisterà finché saremo al mondo, ricreandosi e risuscitando nei punti piú diversi della terra. (Ginzburg, 1999, p. 22).

Somos cinco hermanos. Vivimos en distintas ciudades y algunos en el extranjero, pero no solemos escribirnos. Cuando nos vemos, podemos estar indiferentes o distraídos los unos de los otros, pero basta que uno de nosotros diga una palabra, una frase, una de aquellas antiguas frases que hemos oído y repetido infinidad de veces en nuestra infancia, nos basta con decir: "No hemos venido a Bérgamo a hacer campamento" o "¿A qué apesta el ácido sulfhídrico?", para volver a recuperar de pronto nuestra antigua relación y nuestra infancia y juventud, unidas indisolublemente a aquellas frases, a aquellas palabras. Una de aquellas frases o palabras nos haría reconocernos los unos a los otros en la oscuridad de una gruta o entre millones de personas. Estas frases son nuestro latín, el vocabulario de nuestros días pasados, son como los jeroglíficos de los egipcios o de los asirio-babilonios: el testimonio de un núcleo vital que ya no existe, pero que sobrevive en sus textos, salvados de la furia de las aguas, de la corrosión del tiempo. Estas frases son la base de nuestra unidad familiar, que subsistirá mientras permanezcamos en el mundo, recreándose y resucitando en los puntos más diversos de la tierra. (Ginzburg, 2017b, pp. 37-38).

El hecho de pertenecer a una familia antifascista que sufrió, bajo el dominio del totalitarismo, las persecuciones políticas y el exilio de familiares, dejó marcas en la joven Natalia. Pero fue la experiencia devastadora de la guerra, con la muerte bajo tortura de su marido, la que la llevó al abismo de pensar en el suicidio y por poco disolvió las esperanzas de una vida futura. Es decir, el trauma de la pérdida de los afectos y de un mundo definitivamente desaparecido en el pasado dejó su imperecedera impronta en toda su escritura, atravesada profundamente por el tema de las relaciones familiares.

En 1963, en la revista Successo, Natalia Ginzburg publicó "Raccontare il vero", un texto en el que enfatizaba que su novela era un libro de memorias en el que ella estaba muy poco presente, en el que había querido contar la historia de su familia y de las personas que habían vivido junto a ella desde su infancia. Aseveraba, en este escrito posterior a la publicación de su gran novela, que todo lo contado allí era verdad, una realidad revivida a su modo y como 
ella quería. No había nada inventado, según la autora, y todo había nacido de una multitud de recuerdos:

Perché sulla traccia di quelle frasi, parole e storie, m'era venuto l'impulso di ricercare e far rivivere sia l'atmosfera in cui venivano pronunciate, sia le persone che usavano pronunciarle: e cioè l'atmosfera di casa mia, e le figure dei miei genitori, dei miei fratelli, dei loro amici, e degli amici miei. (En Scarpa, 1999).

Traducción:

Porque en la estela de esas frases, palabras e historias, tuve el impulso de investigar y revivir tanto el ambiente en el que se pronunciaban como las personas que solían pronunciarlas: es decir, el ambiente de mi hogar, y las figuras de mis padres, mis hermanos, sus amigos y mis amigos. (Ginzburg, en Scarpa, 1999).

No obstante hacer estas aclaraciones sobre la materia veraz de su libro, la Ginzburg consideraba que Lessico famigliare tenía que ser leída como una novela, ya que, como ella misma lo confiesa, no se había preocupado por ser tan fiel a la realidad como lo exige la crónica y la historia. Los hechos históricos están presentes, pero se hallan entretejidos con la memoria personal.

\section{Las palabras de la tribu y las de los otros}

En el mundo familiar del niño Marcel, las palabras rememoradas exhiben los rasgos de la cháchara, una peculiaridad asimilable a la de los salones que abisma los intercambios de la vida cotidiana al vacío. Un ejemplo de lo vacuo de las conversaciones se encuentra en la segunda parte de Du côté de chez Swann, en la que también tiene lugar la famosa escena de la magdalena embebida en el té. El narrador recuerda alguno de los diálogos entre Francisca, la criada y la tía Leoncia ${ }^{9}$. Esta conversación, que en definitiva subsumiría en sí el carácter de casi todos los intercambios producidos entre esos dos personajes, revela una forma de comunicación centrada en las nimiedades de la vida cotidiana, una característica a la que no escapan por completo las conversaciones entre los adultos familiares de Marcel. Recordemos cómo el discurso de la tía no va al punto, da vueltas para decir lo que ya se sabe, cuando se trata simplemente de expresar que Swann está haciendo su acostumbrada y casi rutinaria visita a los Proust.

El nombre de Swann se menciona por primera vez cuando se alude a la acostumbrada visita del vecino de los Proust. Este nombre tiene varios significados. Para el niño Marcel, significa tener que abandonar la velada de los adultos para retirarse a su cuarto y dar lugar así al comienzo de un sufrimiento verdadero para él, pues debe alejarse de su madre y esperar hasta tarde su anhelado beso de buenas noches. Para su familia, el nombre funciona como una máscara, puesto que le impide saber que su vecino ya no pertenece a la misma clase social de sus antepasados y que en realidad es "uno de los más elegantes" y "mimados" (Proust, 1982, p. 27) hombres de la alta sociedad de Saint-Germain que visita su casa. Es principalmente la tía la que resulta revelada en su equivocada percepción de las cosas y de Swann, 
contundentemente ridiculizada desde su lugar de certidumbres erróneas, un aspecto que subraya la voz narradora al sostener:

Même au point de vue des plus insignifiantes choses de la vie, nous ne sommes pas un tout matériellement constitué, identique pour tout le monde et dont chacun n'a qu'à aller prendre connaissance comme d'un cahier des charges ou d'un testament; notre personnalité sociale est une création de la pensé des autres. (Proust, s. f., p. 40). ${ }^{10}$

$\mathrm{Ni}$ siquiera desde el punto de vista de las cosas más insignificantes de la vida somos los hombres un todo materialmente constituido, idéntico para todos, y del que cualquiera puede enterarse como de un pliego de condiciones o de un testamento; no, nuestra personalidad social es una creación del pensamiento de los demás. (Proust, 1982, p. 31). ${ }^{11}$

El nombre de Swann también le permite al narrador evocar una anécdota referida al padre de su vecino, viejo amigo de su abuelo. Cuando el entierro de la señora Swann, el padre dice una frase que el abuelo de Marcel adoptará para siempre:

«C'est drôle, je pense très souvent à ma pauvre femme, mais je ne peux y penser beaucoup à la fois». «Souvent, mais peu à la fois, comme le pauvre père Swann», était devenu une des phrases favorites de mon grand-père qui la prononçait à propos des choses les plus différentes. (Proust, s. f., p. 33).

"¡Qué cosa tan rara! Pienso muy a menudo en mi pobre mujer; pero mucho, mucho de una vez no puedo pensar en ella". Y "a menudo, pero poquito de una vez, como el pobre Swann", pasó a ser una de las frases favoritas de mi abuelo, que la decía a propósito de muy distintas cosas. (Proust, 1982, p. 26).

Esta última frase, "pasó a ser una de las frases favoritas de mi abuelo, que la decía a propósito de muy distintas cosas" (Proust, 1982, p. 26), podría concebirse como el núcleo generador de todo el Lessico famigliare. Todo el libro de la Ginzburg gira sobre este modo de operar: alguien, en una situación, dijo alguna vez una frase; esa frase fue recogida y repetida por otros y pasó a ser parte del acervo familiar y, de ahí en más, circula y se repite entre los integrantes de la familia en situaciones muy diversas de aquella en la que tuvo lugar primero. Decir quién las dijo, cuál fue su origen, guiar al lector sobre cómo eran usadas y, muy especialmente, repetirlas una y otra vez en el texto, evidencia la influencia que la lectura de la Recherche provocó en Natalia Ginzburg, obra precursora de su novela, con la cual dialoga.

Deleuze (1995) advierte que no solo es significativo el tiempo perdido del pasado, sino también el tiempo de la vida que se pierde, la experiencia de una vida estéril. Es el caso de la tía que vive encerrada en su cuarto, aguardando la muerte, pendiente de acontecimientos sin ninguna importancia o trascendencia: 
-Françoise, imaginez-vous que Mme Goupil est passée plus d'un quart d'heure en retard pour aller chercher sa sœur ; pour peu qu'elle s'attarde sur son chemin cela ne me surprendrait point qu'elle arrive après l'élévation.

-Hé ! Il n'y aurait rien d'étonnant, répondait Françoise.

-Françoise, vous seriez venue cinq minutes plus tôt, vous auriez vu passer Mme Imbert qui tenait des asperges deux fois grosses comme celles de la mère Callot; tâchez donc de savoir par sa bonne où elle les a eues. Vous qui, cette année, nous mettez des asperges à toutes les sauces, vous auriez pu en prendre de pareilles pour nos voyageurs. (Proust, s. f., pp. 115-117).

-Francisca, figúrese usted que la señora Goupil ha pasado a buscar a su hermana un cuarto de hora más tarde que de costumbre; por poco que se retrase en el camino, no me extrañará que llegue a la iglesia después de alzar.

- Sí, no tendría nada de particular — contestaba Francisca.

- Francisca, si llega usted a venir cinco minutos antes, ve usted pasar a la señora de Imbert con unos espárragos dos veces más gordos que los de la tía Callot; a ver si por medio de su criada se entera usted de dónde los saca. Porque usted, que este año nos pone espárragos en todas las salsas, podría comprarlos de esos para nuestros huéspedes.

- No tendría nada de particular que fuesen de casa del señor cura — decía Francisca. (Proust, 1982, p. 73).

A través de los diálogos recordados de las tías con Swann o de Francisca y el jardinero, por ejemplo, son retratados los mundos contrapuestos de la los ricos, los sirvientes y sus preocupaciones. Las palabras de Francisca contra el heroísmo y la guerra se recuperan en la memoria tanto en sus significados como en su sonoridad:

-Da gusto, ¿eh!, señora Francisca, ver a esos mozos que no tienen apego a la vida — decía el jardinero para sacarla de sus casillas.

— ¡No tener apego a la vida! Entonces, ¿a qué se va a tener apego? La vida es lo único que Dios no da dos veces. ¡Ay, Dios mío!, pero sí que es verdad que no le tienen aprecio. Los vi el año 70, y en esas malditas guerras ya no tienen miedo a la muerte. Son locos; nada más que locos. Y no valen un ochavo; no son hombres, son leones. (Para Francisca, comparar un hombre a un león, palabra que pronunciaba le-ón, no era nada halagüeño.). (Proust, 1982, p. 112).

Como advierte Adorno (2003), solemos no escuchar la realidad, no prestamos atención a cómo suena y solo bastaría tomarse la molestia de disponer los oídos a todo aquello que acompaña a lo dicho para poder percibir cuánto de armónico, de afán de dominio, de falso o halagador hay en la propia voz y en la de nuestro interlocutor. Esta fue una capacidad que Proust se propuso conservar para siempre, intentando mantenerse fiel a un modo de percibir como el primer día, sin deformaciones, el mundo. Un intento, sin duda, de buscar la verdad a través de las palabras, algo que unas décadas después, en otros territorios no muy lejanos, persiguió la autora de Lessico famigliare. 
Escuchar la realidad, como propone Adorno, implica también rescatar de la acción devoradora de Cronos la musicalidad de la lengua poética, no solamente de la consagrada, sino de la de raigambre popular y familiar a través de dichos y canciones. Es notable, en este sentido, cómo lo que apenas aparece esbozado en Proust, a través de la citación de versos de algún poeta francés o de la misma Francisca ("Qui du cul d'un chien s'amourose Il lui paraît une rose" [Proust, s. f., 262]; "Del trasero de un perro se enamorica, / y llega a parecerle cosa bonica" [Proust, 1982, p. 152]), se amplifica y vuelve estrategia recurrente en la obra de la Ginzburg. Así, los versos que compone la autora de niña, los que aprende en libros escolares y los que recuerda que su madre creó son citados en las páginas de Lessico famigliare junto a los de los grandes poetas como Dante. La poesía, la más alta y la más baja, se entrelaza con la vida y ambas se resignifican en un juego eterno: por ejemplo, los poemas que la señora Levi escribió cuando estaba en el internado pasan a ser parte de la historia y del idiolecto familiar al ser recitados, repetidos una y otra vez por ella, para sus hijos:

Mi madre había estado en un internado muchos años y allí se había divertido muchísimo.

Recitaba, cantaba y bailaba en las fiestas, había actuado en una comedia disfrazada de mona y había cantado en una opereta que se llamaba La pantufla perdida en la nieve.

Había compuesto una ópera que comenzaba así:

Yo soy don Carlos Tadrid,

iy soy estudiante en Madrid!

Mientras iba una mañana

Por la calle Berzuellina,

¿a una joven maestra

vi de pronto en la ventana?

Son también frases portadoras de una historia personal, en la que quedan retratadas tanto las costumbres de cierta clase social (las niñas de clase alta iban a los internados) como las actividades que se solían llevar a cabo en las fiestas escolares (cantar operetas y disfrazarse).

No falta en esta novela autobiográfica (¿o novela familiar? ${ }^{12}$ ) de la escritora italiana una relación similar a la planteada más arriba, en el fragmento citado de la Recherche. En el mundo de la señora Levi, tienen lugar felices conversaciones con Natalina, la criada, y Rina, una mujer que realizaba trabajos de costura a domicilio. Aquí también el diálogo recreado se produce entre dos mujeres de distinta condición social y los contrastes y afinidades de esas dos visiones del mundo muestran la complejidad de las relaciones humanas mediadas por la palabra y cómo, pese a todo, entre los seres prima la intención comunicativa y abre caminos en los que las voces se encuentran y dialogan. Proust y Ginzburg recuperan el léxico que resuena en la memoria, frases y palabras de lo cotidiano, banalidades a las que el siglo XX les dio una morada literaria y que, de otro modo, se hubieran perdido para siempre junto a las vivencias de quienes las dijeron:

“¡Estoy helada! -decía mi madre, pero lo decía alegremente, porque le gustaba mucho el agua fría-. ¡Sigo helada! ¡Qué frío hace!” Y se iba a dar una vuelta por el jardín, envuelta en el albornoz y con su taza de café en la mano. En ese momento había en la casa un poco de paz, porque todos mis hermanos estaban 
en la escuela. Mi madre cantaba y se secaba el pelo al aire de la mañana y después iba al cuarto de la plancha a hablar con Natalina y Rina.

Al cuarto de la plancha se le llamaba también "el cuarto de los armarios". En él había una máquina de coser, y Rina se pasaba muchos ratos allí cosiendo. Esta Rina era una especie de sastra, pero sólo servía para volver del revés los abrigos y poner parches a los pantalones, pues no hacía vestidos. Cuando no venía a nuestra casa, iba a la de los Lopez; mi madre y Frances la compartían. Era una mujer bajísima, una especie de enana. Llamaba a mi madre "señora maman", y cuando veía a mi padre por el pasillo escapaba como un ratón, porque él no la podía soportar. (pp. 50-51).

Según mi madre, Natalina se parecía a Luis XI. Era bajita y grácil, y tenía la cara alargada y grácil. Unas veces llevaba el pelo arreglado y otras veces suntuosamente rizado con las tenacillas. "mi Luis XI", decía mi madre cuando la veía entrar en su dormitorio por las mañanas: torva, con una bufanda al cuello y con el cubo y el cepillo en la mano, Natalina confundía los pronombre femeninos y masculinos. Decía a mi madre: "Ella ha salido esta mañana sin el abrigo”. “QQuién es ella?” "El señorito Mario, él debe decírselo”. "¿Quién es él?" "Él, señora Lidia”, decía Natalina ofendida, dando golpes con el cubo. (p. $52)$.

Natalina trataba a mi madre de una forma áspera, sarcástica y nada servil. Pero, sin embargo, las dos se querían tiernamente. "Menos mal que él es una señora, si no, no sé cómo haría para ganarse la vida, él que no sirve para nada”, decía a mi madre. “Él, ¿quién?” “iÉl, usted, usted!”. (p. 53).

Innegablemente, el humor halla su camino en esa confrontación de los idiolectos de la ama y la criada, revelando las diferencias de clases y de educación de los personajes. Recordemos el pasaje de la Recherche... en el que la tía sospecha de la honestidad de su criada de toda la vida y cómo ese altercado se resuelve en fidelidad amorosa. Tanto Proust como Ginzburg se mostraron atraídos por esos personajes de clase social baja y exhiben en sus textos un interés marcado por sus formas de expresión y sus concepciones del mundo presentadas como extrañas para las voces narradoras.

\section{Los lugares de la memoria}

La réalité que j'avais connue n'existait plus. Le souvenir d'une certaine image n'est que le regret d'un certain instant et les maisons, les routes, les avenues, sont fugitives, hélas comme les années.

Marcel Proust

Podríamos sostener que toda la Recherche está estructurada esencialmente sobre la base de una topografía de la memoria, una cronotopía que se sostiene desde el principio en los títulos mismos de los volúmenes y las partes que los constituyen ("Du côté chez Swann", "Le côtè de Guermantes", "Combray"). El consecuente paso del tiempo, expresado en las distintas edades de una vida, está asociado a determinados espacios, como el de Combray a la infancia, 
el de Balbec a la adolescencia o el de la adultez a París. Todo esto no hace más que poner de relieve los tres ejes que vertebran la obra, "el espacio y el tiempo reunidos por un yo" (Fernández Cardo y González, 2006, p. 89) ${ }^{13}$ que busca, a través de las impresiones, llegar a una verdad primera.

Sin lugar a dudas, los lugares en los que se ha habitado quedan grabados en la memoria para siempre. La memoria está albergada (Bachelard, 2000): en el cuarto de Marcel, el sueño y el recuerdo actúan sobre su espíritu tensionado que se desvela a mitad de la noche. Para poder saber quién es, necesita saber dónde está y ser auxiliado por el recuerdo que "venait à moi comme un secours d'en haut pour me tirer du néant d'où je n'aurais pu sortir tout seul" (p. 12); "descendía hasta mí como un socorro llegado de lo alto para sacarme de la nada, porque yo solo nunca hubiera podido salir" (p. 14). El cuerpo, más bien el recuerdo de una determinada postura del cuerpo en la cama, transporta al yo narrador a otros espacios: a Tansonville, muchos años después de haber estado en la casa de sus abuelos en Combray. Y, así, una a una, va evocando todas las alcobas en que ha habitado durante su vida: cuartos de invierno que separan del frío exterior, cuartos de verano que se abren a las noches de verano, alegres alcobas estilo Luis XVI, un pequeño y aromático cuarto en el que domina un espejo, indiscutible objeto relacionado a la identidad y al yo ${ }^{14}$. La costumbre vuelve habitable los espacios en los que el alma no se siente a gusto, pero tan solo un cambio de iluminación, una impresión diferente, puede convertir el cuarto en un espacio doloroso: la linterna mágica no logra distraer al pequeño Marcel. Por el contrario, lo lleva a no reconocer su habitación, a sentir miedo ante las imágenes que se proyectan en las paredes, cancelando el orden reconocible y en parte amparador de su alcoba, esa que, pese a todos los intentos por evitarlo, se vuelve el lugar de la soledad y del abandono por parte de la madre y la abuela.

Desde las primeras páginas, el narrador recuerda un estado bastante indefinido entre la vigilia y el sueño, en el espacio íntimo del dormitorio, de noche, cuando los miedos infantiles (el del aterrador tío que le tiraba de los bucles, por ejemplo) lo abruman y lo confunden. No tarda mucho esa voz narradora en ir de la memoria corporal (el hecho de dormir en cierta posición mala para su cadera le produce un dolor profundo) a la memoria de los lugares habitados, los cuales son, para Ricoeur (2014), "por excelencia, memorables" (p. 64). De acuerdo con este mismo autor, la memoria corporal abre el paso a la memoria de los lugares, los cuales no son menos fugitivos que los años (Guzzo, 2018, p. 154). El espacio y el tiempo se vinculan inmediatamente a las otras voces. A menudo ocurre que, después de cenar, al niño Marcel le pesa tener que separarse de su madre, quien se queda "hablando con los otros" (p. 21). Se produce entonces el ingreso en escena de las palabras, las frases dichas, llenas de intenciones, entre los parientes y que el niño no alcanza a comprender plenamente: «Bathilde! viens donc empêcher ton mari de boire du cognac!» (p. 25) ["Matilde, ven y no dejes a tu marido que beba coñac"], decía la tía de Marcel a su abuela para molestarla. El narrador explica (y esta explicación necesita ser realizada para que el lector comprenda la lógica de las relaciones y el léxico de la tribu) que su abuelo no podía beber licor y, cómo de este modo su tía buscaba "hacer rabiar" a su abuela porque "elle avait apporté dans la famille de mon père un esprit si différent que tout le monde la plaisantait et la tourmentait)" (p. 25); "porque había llevado a la familia de mi padre un carácter tan diferente, que todos le daban bromas y la atormentaban" (p. 22).

Como es posible advertir, el espacio no solo tiene que ver con los lugares en que se habitó, sino también con el espacio que cada uno ocupa en la familia y en la sociedad.

La topografía está presente en la obra de Natalia Ginzburg hasta límites insospechados y no solamente organiza el recuerdo en Lessico famigliare, sino que es un tópico importante también en su ensayística. Los lugares de la memoria ginzburiana están vinculados al tema familiar, entrelazados con los tiempos y los seres ${ }^{15}$, una característica que lleva a Elisabetta Mondello (2017) a hablar de una verdadera poética del espacio en la autora y a advertir que 
no son muchos los escritores que pueden exhibir en la literatura italiana del Novecento un valor evocativo tan continuo en lo que concierne a una topografía mnémica compuesta por habitaciones, casas y ciudades a lo largo de más de medio siglo. El espacio interior (los lugares habitados por los Levi, como las casas de via Pallamaglio y la de via Pastrengo) se entrelaza con los espacios exteriores (las ciudades, las calles, entre otros). La propia Ginzburg reconoció cuán decisiva fue en su poética la lección de Proust, ya que en ella los espacios refigurados son fruto de una vivencia personal y subjetiva activada por el recuerdo (Mondello, 2017). La casa familiar como refugio o tana, la necesidad de abandonarla al crecer e independizarse, la elección del propio lugar para habitar, todo esto se halla presente en la escritura ginzburiana tanto como el espacio mismo de la calle, lugar de encuentro con los otros y símbolo de la vida, de camino recorrido a través del tiempo ${ }^{16}$.

Un componente importante en la casa de la infancia es que allí viven los seres del pasado, familiares y amigos, visitas que suelen frecuentar los recuerdos. Así como el hogar de los Proust recibe, en $D u$ côté de chez Swann, a ese vecino del que creen saberlo todo y, sin embargo, ignoran mucho (el personaje de Swann es visto por el niño desde el punto de vista de sus relaciones con los adultos), en Lessico famigliare, en la casa de los Levi, también se reciben personajes públicos de los que es mejor no decir el verdadero nombre, ya que en el contexto del fascismo el apellido Turati, por ejemplo, resultaba decididamente peligroso. No es extraño que los nombres de gente importante de la vida política y literaria aparezcan en las memorias de escritores y contribuyan a la construcción de un ambiente cultural que, en el caso de la Ginzburg, destaca orgullosa y manifiestamente su linaje antifascista, un rasgo para nada secundario si se considera el contexto represivo del totalitarismo mussoliniano, con su imposición de un discurso único y hegemónico.

\section{Autofiguraciones de escritores niños: infancia y soledad}

Hemos mencionado varios aspectos en los que Lessico famigliare exhibe marcas de afinidad con su hipotexto, Du côté chez Swann. En lo que concierne al yo que rememora la infancia, coinciden Proust y Ginzburg en crear, a través de las voces narradoras, determinadas autofiguraciones de niños solitarios en el mundo adulto, una experiencia que los hace experimentar como seres humanos la excepcionalidad y que los lleva a la búsqueda de la literatura como la mejor compañía. Tanto uno como la otra juegan con el tiempo, intentando representar la génesis de sí mismos como escritores desde la infancia.

Las familias, en este sentido, y muy especialmente las figuras femeninas, resultan de vital importancia en la constitución de esos yo en relación con la literatura. Recordemos la gravitación de la abuela y de la madre en Marcel, y la preponderancia de la señora Levi como fuente y origen de la veta artística en el mundo imaginario de Natalia. La relación con sus madres fue procesada de modo diferente por los escritores. Mientras que, en Proust, al rememorar el pasado deja expuesta la herida sin cerrar del niño que se siente abandonado cuando se separa de su madre por las noches, como si el tiempo no hubiese transcurrido para ese dolor, en Natalia se percibe una evolución que lleva de Natalia Levi, última integrante de esa familia, la que siempre queda descolgada de todo, como en una constelación diferente de los sucesos familiares debido a su corta edad, a Natalia Ginzburg, la escritora.

Es el punto de vista de esa niña que crece rápidamente el que domina al principio de la novela y provoca ese encantador efecto de quien, ya sabiéndolo todo, no lo cuenta y apela a la reticencia, rasgo recurrente de su escritura, como hemos señalado más arriba. La voz narradora se asigna un lugar modesto, el de quien no quiere hablar de sí mismo sino de los otros, de sus familiares, esos que la ven como la más pequeña que entiende poco y nada, que transita un camino que los otros ya han superado hace tiempo. La mirada de esa niña "si ritira in un angolo, si nasconde nella penombra, sta lontano dai grandi. Ocupa poco posto" advierte 
Garboli (1999, p. IX), quien agrega una de las apreciaciones más interesantes sobre este narrador al sostener que el libro de la Ginzburg esconde una "libido animal y agresiva" que no se capta en una primera lectura. Así, siguiendo a Garboli, la paradoja o la ambigüedad se da en el hecho de que la narradora asume una doble función, un doble rol: por un lado, es una espectadora insignificante, y por otro, es quien dirige en forma absoluta esa representación familiar. Por lo tanto, para poder mantener el equilibrio entre esos dos roles incompatibles, debe apelar a ciertas estrategias, como el falso candor, la afectuosa ironía, un aire ligero e infantil, una disposición a recoger todo lo que parece trivial y sin importancia. Los personajes son "aplanados", captados en una sola dimensión:

Ispirati dall'amore, i ricordi della Ginzburg nascono dal bisogno d'insediarsi al centro di uno spettacolo dal quale la Narratrice era e si sentiva esclusa. Se questi ricordi prendono la forma di un romanzo, non lo si deve all'amore ma a un oscuro bisogno di rivendicazione e di possesso. (Garboli, 1999, p. X).

Inspirados por el amor, los recuerdos de la Ginzburg nacen de la necesidad de instalarse en el centro de un espectáculo del cual la narradora era y se sentía excluida. Si estos recuerdos toman la forma de una novela, so se debe al amor sino a una oscura necesidad de reivindicación y de posesión ${ }^{17}$.

El narrador de Proust no deja nunca que olvidemos que quien cuenta la historia, sus recuerdos, es un hombre ya adulto, un escritor, de modo que las anticipaciones o prolepsis aparecen frecuentemente en el texto y resignifican lo rememorado. Quien escribe es quien es por lo que ha vivido: la soledad del niño, por ejemplo, explicaría la del adulto. Ambos escritores tematizan una infancia solitaria y esto los acerca. El contacto con sus pares es tardío y casi inexistente. Marcel no solo padecía limitaciones físicas relacionadas con su salud, sino que vivía rodeado de adultos y, a la vez, separado de ese mundo que lo segregaba por ser pequeño. Natalia, por su parte, última hija de una familia numerosa, no asistió a la escuela primaria, fue educada en casa por su madre, debido a que su padre estaba convencido de que en las instituciones educativas contraería enfermedades graves. Estas experiencias de vida solitarias favorecieron sus relaciones con la literatura y también los marcó indeleblemente.

Pero las realidades de ambos escritores, la clase social a la que pertenecían y las experiencias que dieron forma a sus vidas fueron muy distintas. Proust fue miembro de una clase acomodada y, si bien se interesó por los temas candentes de su época, como el caso Dreyfus, por ejemplo, no dejó nunca de pertenecer a la élite social y cultural de Francia. El universo que él observa lleva las marcas de una descomposición que ya había comenzado en todos los órdenes hacia fines del siglo XIX. Luego de la experiencia de las guerras mundiales, el mundo cambió definitivamente y la Ginzburg supo dar testimonio de esos cambios $^{18}$ tanto como escritora como en su rol de intelectual. La autora italiana eligió el lugar del compromiso social y se enroló en las filas de los que luchaban contra la posibilidad de volver a sufrir nuevamente una experiencia bélica tan dolorosa y extrema como fue la Segunda Guerra Mundial y la destrucción atómica.

No podemos dejar de mencionar que, como escritora, publicó sus ensayos a lo largo de muchos años en la tercera página de los diarios más importantes de Italia, haciendo oír su voz y su opinión sobre los temas políticos y sociales más candentes de su tiempo, una cuestión no 
menor si se entiende cuán diferentes eran las posibilidades para las mujeres intelectuales a principios de siglo pasado.

Hemos intentado hasta aquí definir algunos tópicos y modos en que dialogan las obras de Marcel Proust y Natalia Ginzburg: la memoria, las palabras de la tribu y los espacios son algunos de los aspectos abordados en este breve estudio. No es posible que extendamos, por razones de espacio, nuestro análisis, el que de ningún modo está agotado. Podríamos continuar la relación con algunos otros temas de naturaleza biográfica y artística, como es el doble origen hebreo/católico de ambos autores y la forma en que este hecho impactó en su mundo simbólico y artístico, cuestión que claramente puede vincularse a la topografía literaria que construyen, así como a la característica errancia que exhiben sus narradores. Las resonancias entre ambos textos son variadas y se multiplican, ensanchan el horizonte de las palabras y dan lugar a un diálogo tan profundo y rico entre estos escritores que, como advierte la misma Natalia Ginzburg, pocas veces se encuentran en la vida.

\section{Referencias bibliográficas}

Abes, G. (2020). No caminho de proust: o clássico e suas traduções como acontecimento.
Revista
de
Letras,
$1(39)$.
Recuperado

dehttp://www.periodicos.ufc.br/revletras/article/view/61409

Abignente, E. (2017). Memorie di famiglia. Un genere ibrido del romanzo contemporáneo.

En ENTHYMEMA， (20), 6-17. Recuperado de https://doi.org/10.13130/20372426/9408

Adorno, T. (2003). Notas sobre literatura. Madrid: Akal. Recuperado de https://ia801300.us.archive.org/20/items/246431088AdornoNotasSobreLiteratura/246 431088-Adorno-Notas-Sobre-Literatura.pdf

Arfuch, L. (2014). (Auto)biografía, memoria e historia. Clepsida. Revista Interdisciplinaria de Estudios sobre Memoria, (1), 68-81.

Benjamin, W. (1929). Hacia la imagen de Proust. Recuperado de http://www.agrupacionmayo.com.ar

Bertini, M. (2014). Attraverso Natalia: un percorso proustiano degli anni sessanta. En A. Dolfi (Ed.), Non dimenticarsi de Proust: declinazioni di un mito nella cultura moderna.

Deleuze, G. (1995). Proust y los signos. Barcelona: Anagrama.

Fernández Cardo, J. M. y González, F. (2006). Literatura Francesa del siglo XX. Madrid: Síntesis.

Ferroni, G. (2016). Presenze proustiane in scrittrici del Novecento italiano. En F. Tomassini, I. Antici y M. Piazza (Eds.), Cent'anni di Proust. Echi e corrispondenze nel Novecento italiano. Recuperado de https://www.academia.edu/27241736/Giulio_Ferroni_Presenze_proustiane_in_scrittri ci_del_Novecento_italiano_in_Ilena_Antici_Marco_Piazza_Francesca_Tomassini_a_ cura_di_Cent_anni_di_Proust._Echi_e_corrispondenze_nel_Novecento_italiano_Rom aTre-Press_Roma_2016_pp.19-32

Garboli, C. (1999). "Introduzione” [1963] a Lessico Famigliare. Torino: Einaudi.

Ginzburg, N. (1999). Lessico famigliare. Torino: Einaudi.

Ginzburg, N. (2017a). Cómo he traducido Proust. Zibaldone. Estudios Italianos, V(2), 140144. Recuperado de https://dialnet.unirioja.es/descarga/articulo/6046352.pdf

Ginzburg, N. (2017b). Léxico familiar. Buenos Aires: Lumen. Guzzo, V. (2018). Sobre cuatro habitaciones proustianas. En A. Melamed (Coord.), Actas de las II Jornadas Marcel Proust. Recuperado de https://libros.fahce.unlp.edu.ar/index.php/libros/catalog/book/121 
Horia, V. (1989). Introducción a la literatura del Siglo XX. Santiago de Chile: Andrés Bello. Mattarucco, G. (2014). Natalia Ginzburg Traduttrice. KWARTALNIK NEOFILOLOGICZNY, $L X I$.

Miguel y Canuto, J. C. (2011). El camino que lleva a Natalia Ginzburg: el Lessico famigliare desde dentro. EPOS, XXVII, 249-264.

Mondello, E. (2017). La casa e la città. L'interno e l'esterno. Note sulla poetica dello spazio di Natalia Ginzburg. Bollettino di italianistica. Rivista di critica, storia letteraria, filologia e linguistica, XIV(2).

Pettinotto, J.-P. (2013). Raconter une crise: la mémoire et la vie familiale dans les ouvres de Natalia Ginzburg y Marguerite Duras (Tesis doctoral). Université Lumière Lyon 2, Francia.

Piazza, M. (2016). Gli anni Trenta e le prime letture filosofiche italiane di Proust. En I. Antici, M. Piazza y F. Tomassini (Eds.), Cent'anni di Proust. Echi e corrispondenze nel Novecento italiano. Recuperado de https://www.academia.edu/26467156/Gli_anni_Trenta_e_le_prime_letture_filosofich e_italiane_di_Proust

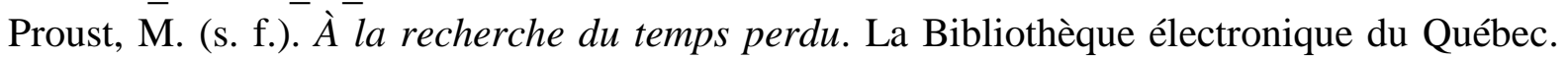
Recuperado de https://beq.ebooksgratuits.com/

Proust, M. (1982). A la búsqueda del tiempo perdido. Buenos Aires: Hyspamérica.

Ricoeur, P. (2014). La memoria, la historia, el olvido. Buenos Aires: Fondo de Cultura Económica.

Scarpa, D. (2020). Falsi amici. Tradurre, (19). Recuperado de https://rivistatradurre.it/falsiamici/

\footnotetext{
Notas

1 “Nel '37, Leone Ginzburg e Giulio Einaudi mi proposero di tradurre À la recherche du temps perdu. Accettai. Era folle propormelo e folle fu da parte mia accettare. Fu anche un atto di estrema superbia. Avevo vent'anni. Non avevo mai tradotto niente ... Proust e la Recherche mi attraevano fortemente (ne avevo sentito parlare in casa) ma ne avevo un'idea confusa e non ne avevo letto una sola riga" (en Mattarucco, 2014, p. 100). El fragmento corresponde a la nota final de la Strada di Swann, escrita en 1990 para una reedición de su traducción primera para la Einaudi. Traducción propia: "En el '37, Leone Ginzburg y Giulio Einaudi me propusieron traducir À la recherche du temps perdu. Acepté. Fue loco proponerlo y fue loco de mi parte aceptar. Fue también un acto de suprema soberbia. Tenía veinte años. No había traducido jamás nada ... Proust y la Recherche me atraían fuertemente (había sentido hablar en casa de él) pero tenía una idea confusa y no había leído una sola línea".

${ }^{2}$ Por ejemplo, las traducciones de Giovanni Raboni y de Franco Fortini.

3 La colección 'Narradores extranjeros traducidos' que había acogido la primera edición de la Strada di Swann había sido proyectada, en 1937, por Julio Einaudi y Leone Ginzburg. A ellos se unió después seguramente Cesare Pavese, integrante fundamental de esa casa editorial. Giulio Einaudi juzgaba que su colección presentaba al público narradores distinguidos y obras de segura difusión entre personas inteligentes. La colección proponía en principio obras como Werther para finalizar con Du côté de chez Swann. Domenico Scarpa señala que Proust era entonces, desde el principio, el coronamiento de todo ese proyecto y que, en el año 1949, la iniciativa de llevar la Recherche a la colección "Supercoralli" fue una apuesta no solo empresarial, sino también de política cultural (Scarpa, 2020).

${ }^{4}$ Todas las citas en italiano corresponden a la edición de Einaudi de 1999.

5 Las respectivas traducciones de las citas del italiano al español pertenecen la edición de Lumen de 2017 (traducción de Mercedes Corral).

${ }^{6}$ Debenedetti percibió que Natalia Ginzburg, en lugar de adaptar su propio tono hogareño al de Proust, en su traducción buscó equivalentes en su propia lengua familiar, intentando lograr un sabor y ternura equivalentes. Sostenía que el dialecto de familia de la Ginzburg había sido colocado a reproducir las funciones del dialecto de la familia Proust. Es decir, se percibía sabor a otra charla hogareña, la de una casa donde había una señorita con una inocencia traviesa, perteneciente a una burguesía diferente a la de la casa Proust. Había, entonces, una
} 
intrusión, una especie de sancta simplicitas que no debía confundirse, advertía Debenedetti, con el candor poético (en Scarpa, 2020).

${ }^{7}$ La memoria y el recuerdo no son lo mismo. No acostumbramos a hablar de la primera en plural, y esto debido a que la memoria es una capacidad y una efectuación. Por el contrario, los recuerdos se distinguen, se pueden delimitar más o menos precisamente sobre ese fondo memorial parecido a un ensueño por su imprecisión (Ricoeur, 2004).

${ }^{8}$ Es un acontecimiento porque sucedió, tuvo lugar (Ricoeur, 2014).

9 "Y Francisca respondía riéndose: 'La señora lo sabe todo, es peor que los rayos X (y decía X con una dificultad afectada y una sonrisa para burlarse de su ignorancia, que se atrevía a emplear ese término científico), que trajeron para la señora Octave y que ven lo que tiene uno en el corazón"” (Proust, 1982, p. 72).

${ }^{10}$ Todas las citas en francés corresponden a la edición de la Biblioteca electrónica de Quebec.

${ }^{11}$ Todas las citas en español corresponden a la edición de Hyspamérica, 1982 (traducción de Pedro Salinas).

${ }^{12}$ Elisabetta Abignente (2017) se propone definir un género que se encuentra entre los confines de la saga familiar y las múltiples escrituras del yo, un género híbrido de la novelística del siglo XX que podría definirse como memorias de familia o novelas familiares de tipo autobiográfico. La autora entiende que Léxico familiar sería una especie de modelo de este género híbrido.

${ }^{13}$ A los que habría que agregar un cuarto elemento, el de la escritura o producción de signos, aspecto que subraya Deleuze (1995) al señalar la forma en que el propio Proust concibió su obra como una máquina o instrumento productor de signos para provocar un determinado efecto en el lector. Para el autor de "Proust y los signos", entonces, la unidad de la obra no estaría dada centralmente por la memoria o el recuerdo involuntario, sino por la búsqueda de la verdad, lo que implica un aprendizaje (la novela podría ser leída como un Bildungsroman): el de un hombre de letras que va aprendiendo a través de decepciones y revelaciones sobre la "mundanidad" (1995, p. 41), el amor y el arte.

${ }^{14}$ Víctor Guzzo (2017) sostiene que En busca del tiempo perdido es una obra sobre los espacios y que los grandes temas de la novela (identidad, subjetividad y arte) están íntimamente relacionados con ellos.

${ }^{15}$ En 'La casa e la città. L'interno e l'esterno. Note sulla poetica dello spazio di Natalia Ginzburg", Elisabetta Mondello (2017) destaca que no son muchos los escritores que muestran, en la literatura del siglo XX, la misma continuidad de Natalia Ginzburg en lo que concierne a la atribución de un valor evocativo a las imágenes espaciales y a la narración de algunos lugares propios. La escritora italiana hace coincidir los paisajes reales, concretos, físicos, vividos desde la infancia hasta la vejez, con los paisajes representados, inventados o evocados. Construye, de este modo, una poética del espacio que en sus obras asume las formas de una topografía mnémica compuesta por las habitaciones, casas y ciudades habitadas en el curso de más de medio siglo. Son los alojamientos burgueses de la familia Levi en los que Natalia transcurre la infancia y la adolescencia.

16 Mijaíl Bajtín señala que el cronotopo del camino está vinculado innegablemente a lo biográfico y autobiográfico, es decir, a la idea de desarrollo de una vida.

${ }^{17}$ Traducción propia.

18 “Hay un movimiento de deslizamiento progresivo, perceptible dentro del Lessico, en virtud del cual la voz de Natalia se va emancipando paulatinamente de la influencia materna, de su mundo, para ir afirmando el propio. Es una emancipación costosa, pautada por la lógica maduración personal pero también por los imperativos acontecimientos externos. Ello implica un cambio de tono, que transita de la jovialidad materna a la seriedad y a la angustia filial" (Miguel y Canuto, 2011, p. 256). 